\title{
The role of canopy gaps in the regeneration of coastal dune forest
}

\author{
Matthew J. Grainger and Rudi J. van Aarde
}

Conservation Ecology Research Unit, Department of Zoology and Entomology, University of Pretoria, South Africa, 0002

Corresponding author: Matthew J. Grainger (matthewjamesgrainger@gmail.com)

\begin{abstract}
In regenerating coastal dune forest, the canopy consists almost exclusively of a single species, Acacia karroo. When these trees die they create large canopy gaps. If this promotes the persistence of pioneer species to the detriment of other forest species then the end-goal of a restored coastal dune forest may be unobtainable. We wished to ascertain if tree species composition and richness differed significantly between canopy gaps and intact canopy, and across a gradient of gap sizes. In three known-age regenerating coastal dune forest sites, we measured 146 gaps, the species responsible for gap creation, the species most likely to reach the canopy and the composition of adults, seedlings and saplings. We paired each gap with an adjacent plot of the same area that was entirely under intact canopy and sampled in the same way.
\end{abstract}

Most species (15 out of 23) had higher abundance in canopy gaps. The probability of self-replacement was low for A. karroo even in the largest gaps. Despite this predominance of shade intolerant species, regenerating dune forest appears to be in the first phase of succession with "forest pioneers" replacing the dominant canopy species. The nature of these species should lead to successful regeneration of dune forest.

Keywords: Acacia karroo, gap dynamics, habitat rehabilitation, niche differentiation, shade tolerance, succession. 


\section{Introduction}

Forest trees can be categorised into two major groups, those which can germinate under intact canopy known as "shade-tolerant" (or "climax") species and those which cannot germinate under intact canopy, but require full sunlight, known as "shade-intolerant" (or "pioneer") species (Whitmore, 1989). The maintenance of these two groups of species in the forest canopy is, according to gap-dynamics theory, the result of gap-phase regeneration, a small scale successional sequence that results in a new tree replacing the original canopy individual (Schnitzer \& Carson, 2001). This leads to a shifting mosaic of intact canopy and gaps over time as different individuals take advantage of a canopy gap then eventually die, allowing another individual to take its place. Where small gaps in the canopy occur, shade tolerant species can recruit to the canopy from the sub-canopy (saplings) or the gap can close through lateral infilling (Rebertus \& Veblen, 1993). In large gaps, the increased light availability promotes the persistence of shade intolerant species allowing them to recruit to the canopy (Huston \& Smith, 1987).

The gap-dynamics paradigm has been questioned repeatedly, with some authors suggesting that it is irrelevant in determining composition of forests. In some mature tropical and sub-tropical forests there is little niche separation and species have wide tolerances for light availability (for example, Obiri \& Lawes, 2004; Hubbell et al., 1999). In these forests, the composition of the tree community is unpredictable. The stochastic nature of canopy gap availability and recruitment limitation means that chance plays a greater role than determinism (Brokaw \& Busing, 2000). However, recently Chambers et al. (2009) showed that chance processes become less important and niche processes more important in determining species composition in central Amazonian forest along a gradient of increasing gap size. 
Our interest in gap-dynamics stems from our experiences in a sere of regenerating coastal dune forest undergoing restoration after strip-mining (see study site description and van Aarde, Coe \& Niering, 1996a). Mature coastal dune forest is characterised by a shade tolerant canopy and sub-canopy, but with some shade intolerant canopy species suggesting that large disturbances do occur (Everard, Midgley \& van Wyk, 1995). In regenerating coastal dune forests, the pioneer species, Acacia karroo (this population in coastal dune forest is also referred to as A. kosiensis; Coates-Palgrave 2002), currently dominates the canopy (see van Aarde et al., 1996a, b). Acacia karroo responds quickly to soil disturbances and dominates the tree community wherever fire and grazing are controlled. As these individuals are senescent by about 30 or 40 years of age (Gourlay, Smith \& Barnes, 1996), we increasingly observe them falling and creating gaps in the canopy. If these large gaps promote the persistence of shade-intolerant pioneer species to the detriment of shade-tolerant forest species then the end-goal of a restored coastal dune forest could take a lot longer than previously predicted (between 38.7 and 40.5 years; Wassenaar et al., 2005). In addition, if large gaps do promote shade intolerant pioneers then $A$. karroo may replace itself leading to a stagnation of succession. The use of the A. karroo successional pathway post-mining has been criticised in the past for exactly this reason (West, Bond, \& Midgley, 2000).

Here we intend to investigate if the gap-dynamics paradigm is relevant to the restoration of coastal dune forest. In particular, we wish to ascertain if tree species composition (i.e. assemblage) and richness differs significantly between canopy gaps and intact canopy, and across a gradient of gap sizes. In addition, we wish to ascertain the probability that $A$. karroo will replace itself in the canopy. See Table 1 for a summary of our assumptions and expectations. 
Table 1. A summary of our assumptions and expectations

\begin{tabular}{|c|c|c|c|c|c|}
\hline \multirow{2}{*}{\multicolumn{2}{|c|}{ Variable }} & \multirow[b]{2}{*}{ Assumptions } & \multicolumn{2}{|c|}{ Expectations } & \multirow[b]{2}{*}{ Analysis } \\
\hline & & & $\begin{array}{c}\text { Shade intolerant } \\
\text { trees }\end{array}$ & $\begin{array}{c}\text { Shade tolerant } \\
\text { trees }\end{array}$ & \\
\hline \multirow{2}{*}{$\begin{array}{l}\text { Tree species } \\
\text { composition, } \\
\text { richness and } \\
\text { abundance }\end{array}$} & $\begin{array}{l}\text { In gaps of } \\
\text { various } \\
\text { sizes }\end{array}$ & $\begin{array}{l}\text { Tree species exhibit } \\
\text { niche } \\
\text { differentiation in } \\
\text { terms of shade- } \\
\text { tolerance }\end{array}$ & $\begin{array}{l}\text { Shade intolerant } \\
\text { species will } \\
\text { proliferate in large } \\
\text { gaps as there is } \\
\text { greater available } \\
\text { sunlight }\end{array}$ & $\begin{array}{l}\text { Shade tolerant } \\
\text { species will be } \\
\text { fewer in larger } \\
\text { gaps because } \\
\text { they are out- } \\
\text { competed by } \\
\text { shade intolerants }\end{array}$ & $\begin{array}{l}\text { Spearman's } \\
\text { correlation } \\
\text { coefficient (for } \\
\text { richness, } \\
\text { abundance, and } \\
\text { density) } \\
\text { ANOSIM }\end{array}$ \\
\hline & $\begin{array}{l}\text { Between } \\
\text { gaps and } \\
\text { paired non- } \\
\text { gaps (under } \\
\text { closed } \\
\text { canopy) }\end{array}$ & $\begin{array}{l}\text { Gaps and intact } \\
\text { canopy differ in the } \\
\text { available light that } \\
\text { reaches trees under } \\
\text { the canopy }\end{array}$ & $\begin{array}{l}\text { Shade intolerant } \\
\text { trees will be more } \\
\text { abundant (with } \\
\text { greater species } \\
\text { richness) in gaps } \\
\text { because of high } \\
\text { light availability }\end{array}$ & $\begin{array}{l}\text { Shade tolerant } \\
\text { trees will be } \\
\text { more abundant } \\
\text { and with greater } \\
\text { species richness } \\
\text { under canopy } \\
\text { (non-gap) }\end{array}$ & ANOSIM \\
\hline $\begin{array}{l}\text { Replacement } \\
\text { probabilities - the } \\
\text { probability that a } \\
\text { gap-maker is } \\
\text { replaced by an } \\
\text { individual of the } \\
\text { same species }\end{array}$ & $\begin{array}{l}\text { In gaps of } \\
\text { various size }\end{array}$ & $\begin{array}{l}\text { The tallest } \\
\text { individual of a } \\
\text { canopy species will } \\
\text { be the first to take } \\
\text { over the canopy } \\
\text { position of the gap- } \\
\text { maker }\end{array}$ & $\begin{array}{l}\text { The probability } \\
\text { that a Shade } \\
\text { intolerant tree will } \\
\text { be replaced by an } \\
\text { individual of its } \\
\text { own species will } \\
\text { increase with } \\
\text { increased gap size }\end{array}$ & $\begin{array}{l}\text { The probability } \\
\text { that a shade } \\
\text { tolerant will } \\
\text { replace a shade } \\
\text { intolerant will } \\
\text { decrease with } \\
\text { increased gap } \\
\text { size }\end{array}$ & $\begin{array}{l}\text { Calculation of } \\
\text { probability }\end{array}$ \\
\hline
\end{tabular}




\section{Material and Methods}

Study area

The study was located to the north of the town of Richards Bay $\left(28^{\circ} 43^{\prime} \mathrm{S}, 32^{\circ} 12^{\prime} \mathrm{E}\right)$ in KwaZulu-Natal, South Africa. The climate is humid and subtropical, with a mean annual rainfall of $1458.0 \pm 493.53 \mathrm{~mm}$ (mean $\pm \mathrm{SD}, n=34$ years between 1976 and 2009; data courtesy of Richards Bay Minerals, RBM). Rainfall peaks in February and the mean annual temperature was $23.79 \pm 3.40{ }^{\circ} \mathrm{C}(n=3$ years between 2006 and 2009 ; data courtesy of RBM). The mining company RBM aims to rehabilitate a third of its mined area with indigenous coastal dune vegetation (the remaining two-thirds are to be rehabilitated with commercial plantations). The mining process (described in full in van Aarde et al., 1996a) destroys all vegetation in front of the mine-pond. Prior to mining, topsoil is removed and stockpiled. Immediately after mining, sand dunes are mechanically re-shaped and the topsoil (seeded with annuals; sun-hemps and sunflowers) is replaced and then stabilised using drift-fencing. Seeds of A. karroo are naturally present in the topsoil. After this initial kick-start, management is limited to the removal of nonnative plant species and herbivores and restoration relies on natural successional processes (van Aarde et al., 1996b). Sampling took place in three regenerating coastal dune forest sites aged 33, 26 , and 22 years. Sites younger than 22 years did not have a sufficient number of canopy gaps to allow analysis.

\section{Gap sampling procedure}

Strip-transects $20 \mathrm{~m}$ wide and separated by $50 \mathrm{~m}$ were walked in a North-South direction across the three regenerating coastal dune forest sites. Where we encountered a canopy gap (definition below) which had its central point within the $20 \mathrm{~m}$ strip we recorded its size and 
sampled vegetation within it (see below). This gap-centre method avoids a potential sampling bias toward larger canopy gaps (Nakashizuka, 1984). We calculated the fraction of the site that was under canopy gap as the sum of the areas of all gaps sampled divided by the total area of the strip transects (Runkle, 1992).

\section{Defining and measuring a canopy gap}

A canopy gap was defined as an opening in the canopy stratum formed by the death of a part of a tree, a single tree or a group of trees in which no trees are greater than two-thirds the height of the canopy (Obiri \& Lawes, 2004). In each gap, we identified and measured the longest axis, and a number of equally spaced "offset" lines that bisected the longest axis. We then summed the length of the "offset" lines and multiplied this figure by the distance between the "offset" lines. Therefore, canopy gap area $(A)$ was calculated as: $A=I^{*}(C+D+E)$, where $I$ is the interval between offset lines and $C, D, E$ etc are the lengths of the offset lines.

\section{Sampling within canopy gaps and intact canopy plots}

We paired each gap with an adjacent plot that was entirely under intact canopy, these plots were the same area as the canopy gap and sampled in the same way. We identified and counted all tree species in each gap and intact canopy plot. In addition, we estimated the height (we measured individuals less than $1 \mathrm{~m}$ high with a tape) and diameter at breast height ( $\mathrm{DBH}$; using a diameter tape) of each individual. We recorded trees as belonging to one of three size classes; we refer to these size classes as "seedlings" ( $<15 \mathrm{~cm}$ in height), "saplings" $(>15 \mathrm{~cm}$ and $<5 \mathrm{~cm}$ $\mathrm{DBH})$ and "adults" ( $>15 \mathrm{~cm}$ and $>5 \mathrm{~cm} \mathrm{DBH}$ but $<2 / 3$ canopy height). It is important to note that we used these terms nominally and made no assumptions regarding the age of individual trees. 


\section{Gap-makers \& gap-takers}

The cause of a canopy gap was categorised as being either a fallen tree, a crown-collapse, or a standing dead tree. We recorded the species that had caused the gap (through its death) and the tallest seedling/sapling/adult in the gap that may replace the gap-maker (the gap-taker). An individual was only considered a gap-taker if it had the potential to reach the canopy.

\section{Data Analysis}

We assessed if median gap size in the three sites (33 years old, 26 years old and 22 years old) were significantly different using the Kruskal-Wallis test and associated post-hoc test. For each gap and intact canopy plot, we calculated species richness (using rarefaction), the abundance of stems and density of stems $\left(\right.$ per $\mathrm{m}^{2}$ ). We used Spearman's rank correlation coefficient to assess the correlation between each of these and gap area. In order to assess if the size of a canopy gap influenced species composition we first categorised the size of canopy gaps into one of four size classes. We used the quartiles of the range of gap areas to define these gap size classes - small gaps were $<95 \mathrm{~m}^{2}$, medium gaps were between 95 and $155 \mathrm{~m}^{2}$, large gaps were between 155 and $285 \mathrm{~m}^{2}$ and very large gaps were $>285 \mathrm{~m}^{2}$. Our data did not allow for the use of Canonical Correspondence Analysis, because of the large number of zero values so we followed the advice of Zuur, Leno \& Smith (2007) and used the Analysis of Similarities (ANOSIM). We used ANOSIM to test for differences in the species composition between four size classes, and between canopy gaps and intact canopy plots. Replacement probabilities were estimated by counting the number of gap-takers of a particular species expressed as a proportion of gap-makers replaced (Midgley, Cameron \& Bond, 1995). Differences between canopy gaps and intact canopy plots in terms of tree species richness, abundance, and density was analysed 
using the Wilcoxon rank - sum test. All analyses except Spearman's correlation coefficient were carried out in the R programme ( $\mathrm{R}$ foundation for Statistical Computing, Vienna, Austria, URL http://www.R-project.org). We used Gaphpad Prism (version 3.03, Graphpad Software, San Diego, California, US, URL http://www.graphpad.com) for the Spearman's correlation coefficient analyses.

\section{Results}

Gap characteristics and causes

We measured and sampled in 146 gaps in total $(n=50,42$ and 54 in the 33, 26 and 22 year old sites respectively). Gap characteristics for each site are described in Table 2. The 26 year old site did not have any gaps larger than $450 \mathrm{~m}^{2}$ (Figure 1).

Five species were responsible for the creation of canopy gaps; A. karroo, Allophylus natalensis, Apodytes dimidiata, Brachylaena discolor, and Casuarina equisetifolia. However, A. karroo was the most abundant gap-maker $(99.00 \%$ of all gap-makers, $\mathrm{n}=402)$. There was no significant difference between the number of gap-makers in each site (Kruskal-Wallis test; $H=$ 4.1, d.f. $=4 ; \mathrm{P}=0.13)$. The median gap-makers in all sites were 2 trees per gap. The number of gap-makers per gap was not significantly correlated to gap area $(r=0.10, n=142, P=0.22)$. Fallen trees made up $89.80 \%$ of all gap-makers $(n=402)$. Crown-collapse made up $8.45 \%$ of gap-makers and the remainder (1.74\%) were standing dead.

Only 11 species made up the 165 gap-takers recorded, these were; A. karroo, Albizia adianthifolia, A. natalensis, A. dimidiate, Bridelia micrantha, Celtis africana, Clerodendrum glabrum, Ekebergia capensis, Mimusops caffra, Psydrax obovata and Trichilia emetica. The 
33 year od site

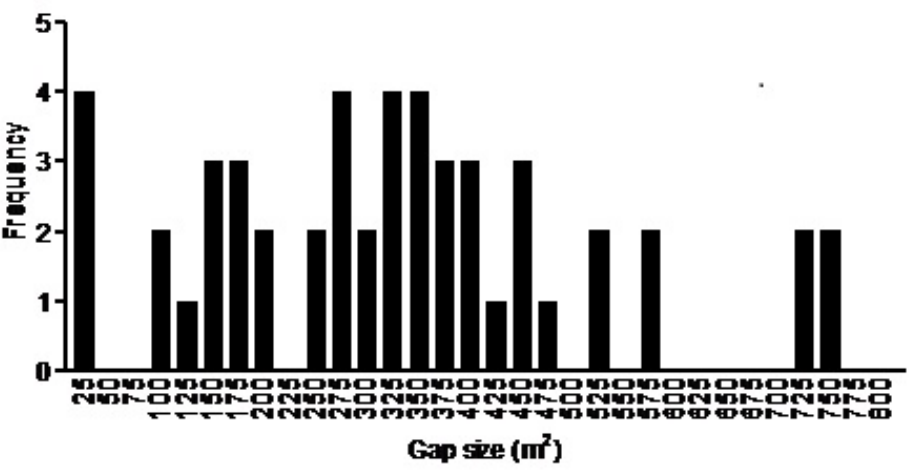

26 year ad ste

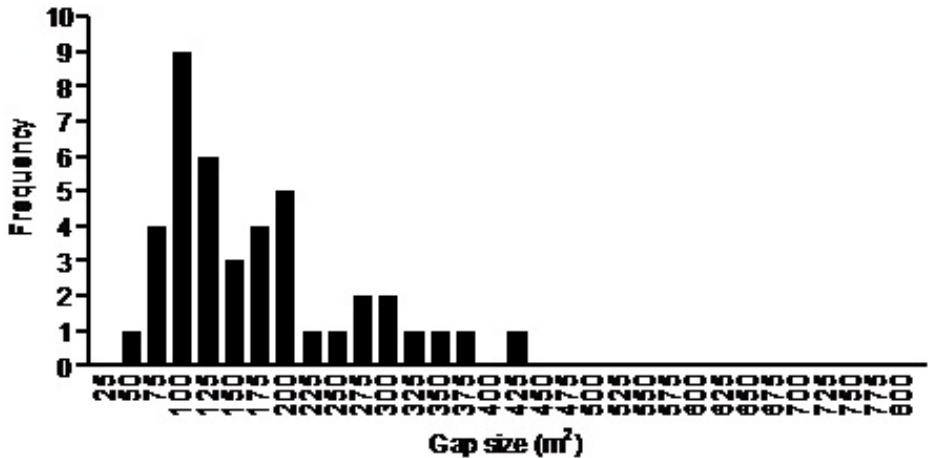

22 year ad ste

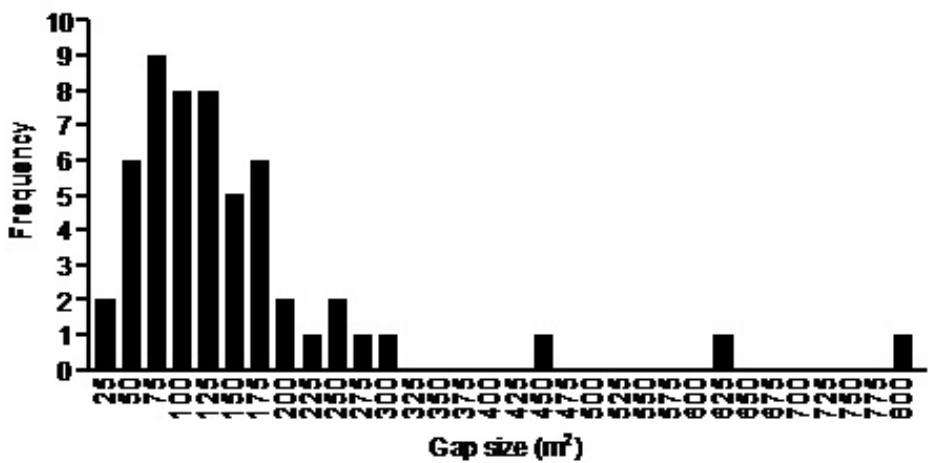

Figure 1. The gap size frequency distribution for the three regenerating coastal dune forests sites. 
Table 2. Gap characteristics in three regenerating coastal dune forest sites. Median gap size differed significantly between the three sites (Kruskal-Wallis test: $H=19.01$, d.f. $=2, \mathrm{P}<0.001$ ). The post-hoc test showed that gaps in the 33 year old site were significantly larger than in the other two sites, but gap size in the 26 and 22 year old sites were similar.

\section{3 year old site $\quad 26$ year old site $\quad 22$ year old site}

\begin{tabular}{|c|c|c|c|}
\hline \multicolumn{4}{|l|}{ Mean \pm standard deviation } \\
\hline diameter at breast height & $23.25 \pm 2.53(n=83)$ & $8.577 \pm 0.61(n=201)$ & $7.39 \pm 0.42(\mathrm{n}=310)$ \\
\hline \multicolumn{4}{|l|}{$(\mathrm{cm})$} \\
\hline Number of gaps measured & 50 & 42 & 54 \\
\hline Area of smallest gap $\left(\mathrm{m}^{2}\right)$ & 97.80 & 27.93 & 15.60 \\
\hline Area of largest gap $\left(\mathrm{m}^{2}\right)$ & 732 & 405.5 & 778 \\
\hline $\begin{array}{l}\text { Mean gap size }\left(\mathrm{m}^{2} \pm\right. \\
\text { standard deviation })\end{array}$ & $352.43 \pm 210.80$ & $149.33 \pm 81.40$ & $149.52 \pm 148.88$ \\
\hline $\begin{array}{l}\text { Percentage of site canopy } \\
\text { composed by gaps }(\%)\end{array}$ & 26.78 & 16.90 & 12.73 \\
\hline
\end{tabular}

most abundant gap-takers were $M$. caffra (25.45\%), C. africana (21.21\%) and E. capensis $(12.12 \%)$. The probability that the gap-taker would be the same species as the gap-maker was zero in the smallest and medium sized canopy gaps. In large and very large canopy gaps, the probability was 0.10 and 0.16 respectively.

Tree species richness, abundance, and density

In total, we recorded 53 species, 38 of these were present in both canopy gaps and under intact canopy. Five species were found only in canopy gaps and nine only under intact canopy (Table 3). However, all these species were relatively rare ( $<10$ individuals recorded). 
Table 3. List of rare species (<10 individuals) found uniquely under canopy gaps and under intact canopy

\begin{tabular}{ll}
\hline Species found uniquely in canopy gaps & Species found uniquely under intact canopy \\
\hline Diospyros natalensis & Antidesma venosum \\
Dovyalis caffra & Diospyros rotundifolia, \\
Maytenus sp. & Drypetes gerrardii \\
Turraea floribunda & Dovyalis zeyheri \\
Xylotheca kraussiana & Acacia sp. \\
& Harpephyllum caffrum \\
& Margaritaria discoidea \\
& Memecylon natalensis \\
& Pavetta revolute
\end{tabular}

For both adults and saplings in canopy gaps and under intact canopy, species richness (per stem), abundance and density (except sapling density: $\mathrm{r}=0.12, \mathrm{n}=142, \mathrm{P}=0.18$ ) significantly increased with sample area (adult richness: $\mathrm{r}=0.24, \mathrm{n}=169, \mathrm{P}<0.001$; adult abundance: $\mathrm{r}=0.42, \mathrm{n}=169, \mathrm{P}<0.001$; adult density: $\mathrm{r}=0.37, \mathrm{n}=169, \mathrm{P}<0.001$; sapling richness: $\mathrm{r}=0.75, \mathrm{n}=142, \mathrm{P}<0.001$; sapling abundance: $\mathrm{r}=0.74, \mathrm{n}=142, \mathrm{P}<0.001)$. Seedlings however, showed no significant correlation between sample area and richness, abundance, or density $(\mathrm{r}=0.31, \mathrm{n}=6, \mathrm{P}=0.32 ; \mathrm{r}=0.20, \mathrm{n}=6, \mathrm{P}=0.71 ; \mathrm{r}=-0.20, \mathrm{n}=6, \mathrm{P}=$ $0.71)$.

The richness, abundance and density of adults did not differ significantly between canopy gaps and under intact canopy (Wilcoxon rank - sum test, $\mathrm{W}=201, \mathrm{P}=0.06 ; \mathrm{W}=201.1, \mathrm{P}=$ 0.06; $\mathrm{W}=181, \mathrm{P}=0.12 ; \mathrm{W}=4337$ ). In contrast, sapling richness, abundance and density were all significantly greater in canopy gaps than under intact canopy (Wilcoxon rank - sum test, $\mathrm{W}=$ 
4909, $\mathrm{P}<0.0001 ; \mathrm{W}=4680, \mathrm{P}<0.0001 ; \mathrm{W}=4337, \mathrm{P}<0.0001)$. For the seedlings, species richness was greater in canopy gaps than under intact canopy $(\mathrm{W}=107, \mathrm{P}=0.02)$, however abundance and density were not significantly different $(\mathrm{W}=88, \mathrm{P}=0.13, \mathrm{~W}=65, \mathrm{P}=0.26$ ).

Species composition - gap area

We excluded rare species $(<10$ individuals) from subsequent analysis. The composition of both adults and saplings differed significantly between gap size categories (ANOSIM, P < 0.05). For adults, of the nine species recorded, five species were equally abundant in all canopygap size classes (Table 4). The remaining four were all significantly more abundant in large or very large gaps (Table 4). Only one individual adult $A$. karroo was recorded in a canopy gap. For saplings, most (17 out of 23) of the species recorded in canopy gaps were recorded in all gap sizes, and half (12 out of 23) showed significant differences in the mean number of stems (per $100 \mathrm{~m}$ ) across the gradient of gap sizes (Table 4). Five species were not recorded in the smallest gap size category (Table 4). Seedling composition showed no significant difference between gap size categories (ANOSIM, P > 0.05).

The composition of adults differed significantly between canopy gaps and intact canopy plots in the 33 year old site only (ANOSIM, $\mathrm{P}<0.05$ ). Of the 9 species in the adult class, 6 had significantly greater abundances in plots in canopy gaps (Wilcoxon rank - sum test, $\mathrm{P}<0.05$, Table 4; Figure 2). The 33 and the 22 year old site showed significant difference in the composition of saplings in canopy gaps compared to intact canopy plots (ANOSIM, $\mathrm{P}<0.05$ ). There was no significant difference in composition in the 26 year old site (ANOSIM, P > 0.05). Ten of the 23 species in the sapling class were equally abundant in canopy gaps and in intact 
Table 4. We assessed if the abundance of each species was significantly different between plots under canopy gaps and plots under intact canopy (matched for sample area) using Wilcoxon rank - sum test. A significant difference is indicated in the table by the labels "Canopy gap" or "Intact Canopy" indicating where the abundance of each species was significantly greater. The label "ns" indicates a non-significant difference in the abundance of a species between canopy gaps and intact canopy. We assessed if the abundance of species differed between the four canopy-gap size classes using the Kruskal - Wallis test with a post test (Dunn's Multiple Comparison Test). The size classes where species had significantly greater abundance are labelled and once again, "ns" indicates a nonsignificant difference between gap size classes.

\begin{tabular}{|c|c|c|c|c|c|c|}
\hline \multirow{3}{*}{ Species } & \multicolumn{6}{|c|}{ Size class } \\
\hline & \multicolumn{2}{|c|}{ Adult } & \multicolumn{2}{|c|}{ Sapling } & \multicolumn{2}{|c|}{ Seedling } \\
\hline & $\begin{array}{c}\text { Canopy gap vs. Intact } \\
\text { canopy }\end{array}$ & Gap size & $\begin{array}{c}\text { Canopy gap vs. Intact } \\
\text { canopy }\end{array}$ & Gap size & $\begin{array}{c}\text { Canopy gap vs. Intact } \\
\text { canopy }\end{array}$ & Gap size \\
\hline Acacia karroo & & & Canopy gap & Large/Very Large & Canopy gap & Large/Very Large $^{1}$ \\
\hline Allophylus natalensis & Canopy gap & Large/Very Large & Canopy gap & Small/Medium & Canopy gap & Very Large $^{1}$ \\
\hline Apodytes dimidiata & & & ns & ns & & \\
\hline Brachylaena discolor & Canopy gap & $\begin{array}{c}\text { Medium/Large/Very } \\
\text { Large }\end{array}$ & Canopy gap & ns & & \\
\hline Bridelia micrantha & & & ns & ns & & \\
\hline Canthium inerme & Canopy gap & ns & Canopy gap & ns & & \\
\hline Celtis africana & ns & ns & ns & Small/Medium & Canopy gap & Very Large $^{1}$ \\
\hline Cestrum laevigatum & Canopy gap & Very Large & Canopy gap & Large/Very Large & & \\
\hline Ekebergia capensis & & & ns & Large/Very Large & & \\
\hline
\end{tabular}




\begin{tabular}{|c|c|c|c|c|c|c|}
\hline Grewia occidentalis & Canopy gap & ns & ns & ns & & \\
\hline Kraussia floribunda & & & Canopy gap & $\begin{array}{c}\text { Medium/Large/Very } \\
\text { Large }\end{array}$ & & \\
\hline Mimusops caffra & Canopy gap & Very Large & ns & ns & & \\
\hline Peddia africana & & & ns & Medium/Large & Intact Canopy & Not in gaps ${ }^{2}$ \\
\hline Psychotria capensis & & & Canopy gap & ns & & \\
\hline Psydrax obovata & & & ns & Small & & \\
\hline Rhus natalensis & & & Canopy gap & Very Large & & \\
\hline Rhus nebulosa & & & Canopy gap & Very Large & & \\
\hline Scutia myrtina & & & Canopy gap & ns & Canopy gap & $\begin{array}{c}\text { Medium/Large/Very } \\
\text { Large }\end{array}$ \\
\hline Teclea gerrardii & ns & ns & ns & ns & & \\
\hline Trema orientalis & ns & ns & ns & ns & & \\
\hline Tricalysia sonderiana & & & ns & Small/Very Large & & \\
\hline Trichilia emetic & & & ns & Large/Very Large & & \\
\hline Zanthoxylym capense & & & ns & ns & Intact Canopy & Large $^{3}$ \\
\hline
\end{tabular}

${ }^{1}$ A. karroo seedlings were only found in large and very large canopy gaps, there was no significant difference in abundance between these two gap size classes (Mann-Whitney test, $\mathrm{P}>0.05)$. A. natalensis and C. africana seedlings were only found in very large gaps and therefore we could not assess significant differences between size classes.

${ }^{2}$ P. africana seedlings were not found in canopy gaps.

${ }^{3}$ Most Z. capense seedlings were found under intact canopy. 

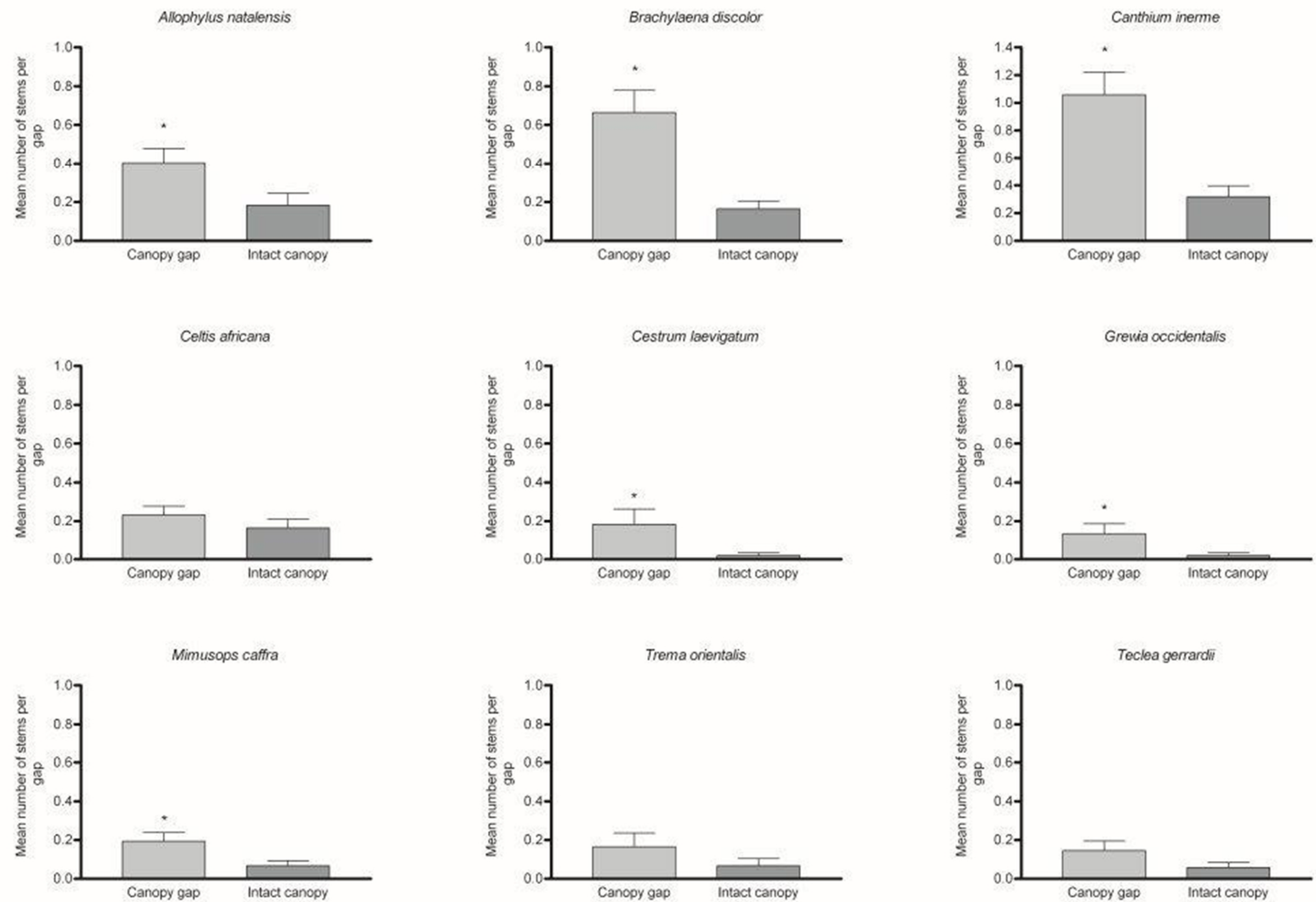

Figure 2. Differences in the abundance (mean number of stems per gap) of adults of nine tree species in rehabilitating coastal dune forest. Significant (alpha $=$ 0.05) differences in abundance as measured using Wilcoxon rank - sum test are indicated by an asterisk. 
canopy plots. The remaining 13 species were more abundant in canopy gaps than under intact canopy.

There was no significant difference in the seedling composition between canopy gaps and under intact canopy in all sites (ANOSIM, P > 0.05). However, only one species (Zanthoxylym capense) had seedlings in both canopy gaps and under intact canopy.

\section{Discussion}

In regenerating coastal dune forest, the canopy consists almost exclusively of a single species, A. karroo, and the death of these trees affects the species composition of dune forest and may shape the future success of restoration. The majority of species (15 out of 23 ) showed nichedifferentiation mostly having higher abundance in large or very large canopy gaps. Shade intolerant species dominate the regenerating sites. This may be considered alarming in the context of a restoration project that aims to restore coastal dune forest, especially as mature coastal dune forest is characterised by shade tolerant species in its canopy and sub-canopy layers (Everard et al., 1995). However, as we shall show here, this predominance of shade intolerant species appears to be a primary stage in coastal forest succession.

An individual $A$. karroo rarely dies alone and the resultant large multi tree-fall gaps

promote the persistence of shade intolerant species (Everard et al., 1995). The majority of canopy gaps in regenerating coastal dune forest formed through tree-fall. Fallen trees cause a larger disturbance in the canopy than standing dead trees or branch-fall due to the physical action of the tree falling, which can damage understorey vegetation. In addition, a fallen tree will no longer intercept light. The short lifespan of $A$. karroo may mean that gaps and multi-tree gaps 
open more readily in regenerating coastal dune forest than in mature forests. The proportion of canopy under gap and the mean gap area were both relatively large when compared to other forests with the exception of boreal forests (Obiri \& Lawes 2004; Vepakomma, Kneeshaw \& Stonge, 2010).

In the 26 and 22 year old regenerating sites, the species composition of the adult size class did not differ significantly between intact canopy and canopy gaps. This suggests that the composition of the adult size class is the same as the sub-canopy prior to the creation of the canopy gap. However, in the 33 year old regenerating site, the adult size class differed significantly between intact canopy and canopy gaps. Despite ensuring that an intact gap-maker was present in each recorded gap it appears that in the oldest site, gaps are old enough to have influenced the adult tree composition. Gap expansion may explain this phenomenon. The original gap maker may have decomposed, and subsequent trees fallen in to the gap. This cascading disturbance is characteristic of some forests where the probability of mortality is greater at the edge of a canopy gap when compared to those in intact canopy (Vepakomma et al., 2010). The greater mean gap size in the oldest site may also be a result of this gap expansion.

Sapling composition differed significantly between intact canopy and canopy gaps for both the 33 and 22 year old sites. Most species were present in both intact canopy and under canopy gaps, but abundances between the two canopy types differed significantly. Very few species were more abundant under intact canopy at any size class. This finding agrees with Rüger et al. (2009) who showed that in tropical rainforest the majority of the tree community regenerate better in higher light. Species in regenerating coastal dune forest appear to regenerate with greater abundance under increased light conditions, as is indicated by the higher abundances in larger canopy gaps for the majority of species. 
Interestingly, the 26 year old site did not show any difference in composition between canopy gaps and intact canopy. One plausible explanation for this may stem from the frequency distribution of gap sizes in this site compared to the other two sites. The 26 year old site had fewer large gaps and no gaps greater than $425 \mathrm{~m}^{2}$. Recently, Chambers et al. (2009) suggested that in small gaps (typical of most forest types) neutral or stochastic processes (e.g. recruitment limitation) determine species composition. In large gaps however (defined as $>1000 \mathrm{~m}^{2}$ by Chambers et al., 2009), pioneer species have a competitive advantage over other species. In our regenerating sites, the smaller gaps may have had similar light conditions to intact canopy where species tended to have similar abundances in both gap and intact canopy suggesting that conditions were similar and tolerances wide. However, in the largest gaps situated in the 22 and 33 year old sites, there was a greater differentiation between gap and intact canopy and more pioneer species (such as A. karroo, C. inerme, and C. laevigatum) than in smaller canopy gaps.

In regenerating coastal dune forest, seedlings were most abundant in canopy gaps. They were absent from small gaps, and with the exception of $P$. africana and $Z$. capense, were absent from intact canopy. This again suggests that the majority of species in the tree community are shade intolerant and very few can tolerate low light levels.

This apparent lack of shade tolerant species is indicative of the characteristics of the current canopy. This canopy, dominated by A. karroo, will not replace itself after senescence. Acacia karroo is a typical pioneer species as it has small and numerous wind dispersed seeds (Coates-Palgrave, 2002). This species had low abundance of seedlings, saplings, and adults under intact canopy, confirming its pioneer status. The probability of $A$. Karroo replacing itself was zero in small and medium sized canopy gaps. In large and very large canopy gaps, the probability increased but was still very low ( 0.10 to 0.16$)$. Therefore, there is only a small 
probability that this pioneer species will replace itself within the canopy. Unless gaps become increasingly larger $A$. karroo will not replace itself and therefore will not remain the dominant tree species.

The most abundant gap-taker was $M$. caffra. This species has a wide tolerance for environmental conditions; it can survive and grow within the salt-spray zone but is also a dominant canopy species within mature coastal dune forest (Coates-Palgrave, 2002). The second most abundant gap-taker was $C$. africana, which is often described as a forest pioneer species (Midgley et al., 1995; Coates-Palgrave, 2002). In our study, C. africana seedlings were more abundant in canopy gaps than under intact canopy, and were only found in the largest canopy gaps. However, at the sapling size class, C. africana were more abundant in small and medium sized gaps. This suggests once again that this species has wide tolerances for light. It appears that the changes in the canopy of regenerating coastal dune forest are deterministic with the longer living pioneer species with wide environmental tolerances replacing the short-lived A. karroo. In the future $M$. caffra and C. africana may fundamentally alter the light penetration in to regenerating coastal dune forest. Both $M$. caffra and $C$. africana are broadleaved species whilst A. karroo has small compound leaves that are smaller in surface area. These tree species may provide more suitable conditions for shade-tolerant species typical of forest than under the present $A$. karroo canopy.

Previous work has predicted that the composition of regenerating coastal dune forest will be similar to an undisturbed coastal dune forest within 40 years (Wassenaar et al., 2005). We have shown here that even if predicted changes in composition do occur, the structure of the forest may take a longer time to mimic an undisturbed dune forest. Regenerating dune forest is currently undergoing the first phase of succession with "forest pioneers" replacing the dominant 
canopy species. The nature of these species (broadleaved) and stochastic generation of canopy gaps should lead to greater heterogeneity in light conditions allowing greater niche space available for shade tolerant species to establish in regenerating sites and lead to the successful regeneration of dune forest.

\section{Acknowledgements}

We thank the University of Pretoria, Richards Bay Minerals and the South African Department of Trade \& Industry for logistical and financial support. We acknowledge the help of Michelle Boshoff of RBM for facilitating fieldwork. Laura Owens and Thabile Khuzwayo assisted with fieldwork. We thank four anonymous reviewers for helpful comments which greatly improved the manuscript.

\section{References}

BROKAW, N. \& BUSING, R.T. (2000). Niche versus change and tree diversity in forest gaps. Trends Ecol. Evol. 15, 183-188.

CHAMBERS, J.Q., ROBERTSON, A.L. CARNEIRO, V.M.C, LINA, A.J.N, SMITH, M.L.,PLORDE, L.C. \& HIGUCHI, N. (2009). Hyperspectral remote detection of niche partitioning among canopy trees driven by blowdown gap disturbances in the Central Amazon. Oecologia 160, 107-117.

COATES-PALGRAVE, K. (2002). Trees of southern Africa. Struik Publishers, Cape Town.

EVERARD, D.A., MIDGLEY, J.J. \& VAN WYK, G.F. (1995). Dynamics of some forests in KwaZuluNatal South Africa based on ordinations and size-class distribution. S. Afr. J. Bot. 61, 283- 292. 
GOURLAY, I.D., SMITH, J.P. \& BARNES, R.D. (1996). Wood production in a natural stand of Acacia karroo in Zimbabwe. Forest Ecol. Manage. 88, 289-295.

HUBBELl, S.P., FOSTER, R.B., O’BRIEN, S.T., HARMS, K.E., CONDIT, R., WECHSLER, B., WRIGHT, S.J. \& DE LAO, S.L. (1999). Light-gap disturbances recruitment limitation and tree diversity in a neotropical forest. Science 283, 554-557.

HUSTON, M., \& SMITH, T. (1987). Plant succession: life history and competition. Am. Nat. 130, 168198.

MIDGLEY, J.J., CAMERON, M.C. \& BOND W.J. (1995). Gap characteristics and replacement patterns in the Knysna Forest, South Africa. J. Veg. Sci. 6, 29-36.

NAKASHIZUKA, T. (1984). Regeneration process of climax beech (Fagus crenata Blume) forests. IV. Gap formation. Jap. J. Ecol. 34, 75-85.

OBIRI, J.A.F. \& LAWES, M.J. (2004). Chance versus determinism in canopy gap regeneration in coastal scarp forest in South Africa. J. Veg. Sci. 15, 539-547.

REBERTUS, A.J. \& VEBLEN, T.T. (1993). Structure and tree-fall gap dynamics of old-growth Nothofagus forests in Tierra del Fuego, Argentina. J. Veg. Sci. 4, 641-654.

RÜGER, N., HUTH, A., HUBBELL, S.P. \& CONDIT, R. (2009). Response of recruitment to light availability across a tropical lowland rain forest community. J. Ecol. 97, 1360-1368.

RUNKLE, J.R. (1992). Guidelines and sample protocol for sampling forest gaps. United States Department of Agriculture general report PNW-GTR-283, Pacific Northwest Research Station, US.

SCHNITZER, S.A. AND CARSON, W.P. (2001). Treefall gaps and the maintenance of species diversity in a tropical rainforest. Ecology 82, 913-919. 
VAN AARDE, R.J., COE, M. \& NIERING, W.A. (1996a). On the rehabilitation of coastal dunes of KwaZulu-Natal. S. Afri. J. Sci. 92, 122-124.

VAN AARDE, R.J., FERREIRA, S.M., KRITZINGER, J.J. \& VAN DYK, P.J. (1996b). An evaluation of habitat rehabilitation on coastal dune forests in northern KwaZulu-Natal, South Africa. Restor. Ecol. 4, 334-345.

VEPAKOMMA, U., KNEESHAW, D. \& ST-ONGE, B. (2010). Interactions of multiple disturbances in shaping boreal forest dynamics: a spatially explicit analysis using multi-temporal lidar data and highresolution imagery. J. Ecol. 98, 526-539.

WASSENAAR, T. D., VAN AARDE, R. J., PIMM, S. L. \& FERREIRA, S. M. (2005). Community convergence in disturbed sub-tropical dune forest. Ecology 86, 655-666.

WEST, A., BOND, W. \& MIDGLEY, J.J. (2000). Dune forest succession on old lands: implications for post-mining restoration. In: Seydack, A.H.W, Vermeulen, W.J., \& Vermeulen, C. (eds.) Towards sustainable management based on scientific understanding of natural forests and woodlands, pp. 35-39. Department of Water Affairs and Forestry, Knysna, ZA.

WHITMORE, T.C. (1989). Canopy gaps and the two major groups of forest trees. Ecology 70, 536-538.

ZUUR, A.F., LENO, E.N. \& SMITH, G.M. (2007). Analysing ecological data. $1^{\text {st }}$ ed. Springer, New York, US. 